\title{
COMPARATIVE STUDY BETWEEN RADIOLOGICAL CLASSIFICATION AND MACRO AND MICROSCOPIC ANALYSIS ON OSTEOARTHRITIS LESIONS OF THE KNEE
}

Carlos Antônio Garrido', Tania Clarete Fonseca Vieira Sales Sampaio², Frederico de Souza Ferreira ${ }^{3}$

\section{ABSTRACT}

Objectives: To compare the modified Ahlbäck radiological classification with macroscopic analysis of knee injuries and locate a chondral lesion in the tibial plateau, and to correlate this with integrity or lack of integrity of the anterior cruciate ligament. Material and Methods: Between July and December 2009, 40 patients of mean age 67.1 years with an indication for total knee arthroplasty were selected. The modified Ahlbäck radiological classification was used. The International Cartilage Repair Society classification was used for macroscopic analysis of the lesions. Chondral injuries were correlated with the integrity or lack of integrity of the anterior cruciate ligament. Results: Regarding the radiological classification of the knees, three $(7.5 \%)$ were classified as grade 1 , two $(5 \%)$ as grade 2, $17(42.5 \%)$ as grade $3,16(40 \%)$ as grade
4 and two (5\%) as grade 5 . The macroscopic analysis of the knee showed that 25 patients $(62.5 \%)$ had very severe injury and 15 (37.5\%), severe. In eight knees (20\%) with ruptured ACL, the lesion extended to the posterior region of the medial tibial plateau. When the ACL was intact, the lesion was located in the anterior-central region. Conclusion: Knee osteoarthritis of grades 4 and 5 in the radiological classification, showed agreement with the macroscopic analysis, i.e. very severe chondral injury. However, grades 1, 2 and 3 were discordant. In the cases of osteoarthritis with intact ACL, the lesion was located in the anterior-central region of the medial tibial plateau, and those with ruptured ACL had the lesion extending to the posterior region of the plateau.

Keywords - Osteoarthritis; Knee; Pathology; Biopsy

\section{INTRODUCTION}

Osteoarthritis (OA) is a progressive degenerative disease of the joint cartilage that can lead to joint deformity. The process initially affects the cartilage and, later, the subchondral bone. Clinically, it is characterized by pain, stiffness, crepitations, bone enlargement and progressive functional limitation ${ }^{(1)}$ It is estimated that symptomatic knee osteoarthritis occurs in $13 \%$ of the population over 60 years, and this number is expected to double by $2020^{(2)}$.
Loss of joint cartilage is a characteristic of osteoarthritis. The width of the joint space is considered an indication of cartilage thickness, therefore narrowing of the joint space is one of the main radiological characteristics of osteoarthritis ${ }^{(3)}$.

Conventional radiograph is a simple, low-cost imaging method for evaluation of knee osteoarthritis. Radiograph allows direct visualization of bone changes, including marginal osteophytes, subchondral sclerosis and subchondral cysts. The evaluation

1 - PhD and Master's Degree in Orthopedics from Unifesp; Orthopedic Doctor and Head of Residency Service of the Hospital São Bento Cardioclínica S/A - Belo Horizonte, MG.

2 - PhD in General Pathology from UFMG; Master's Degree in Rehabilitation from Unifesp; Resident Doctor in Orthopedics and Traumatology at the Hospital São Bento Cardioclínica S/A - Belo Horizonte, MG.

3 - Orthopedic Doctor and Specialist in Knee Surgery at the Hospital São Bento Cardioclínica S/A - Belo Horizonte, MG.

Work carried out at the Hospital São Bento Cardioclínica S/A - Belo Horizonte, MG.

Correspondence: Tania Clarete Fonseca Vieira Sales Sampaio - Rua Agena, 180 - Santa Lúcia - 30360-730 - Belo Horizonte, MG. E-mail: tania@sportsmed.com.br 
of joint space width provides an indirect estimate of cartilage thickness ${ }^{(4)}$.

In 1968, Ahlbäck demonstrated the importance of the anteroposterior (AP) radiograph in the orthostatic position, with the body weight supported by the knee in question ${ }^{(5)}$. It was not until 1980, after a review of 359 knees with medial osteoarthritis, that the Ahlbäck classification was published, described as follows: Grade1: moderate destruction of the cartilage (narrowing of the joint space); Grade 2: complete destruction of the cartilage (obliteration or almost obliteration of joint space); Grade 3: bone wear less than 5 $\mathrm{mm}$; Grade 4: bone wear between 5-15 mm; Grade 5: bone wear greater than $15 \mathrm{~mm}$. The authors ${ }^{(6)}$ indicate that cases with lateral osteoarthritis were not evaluated for this scoring system. Keyes et al modified the Ahlbäck classification, adding the lateral view at $20^{\circ}$ of flexion in the radiographic evaluation ${ }^{(7)}$. These authors correlated the location of the wear on the medial tibial plateau with the integrity, or lack of integrity, of the anterior cruciate ligament, confirming the findings previously described ${ }^{(8)}$.

A problem in osteoarthritis clinical and epidemiological research is the difficulty in correlating degenerative changes with the radiological classifications used. This situation is also observed in knee osteoarthritis. ${ }^{(9-12)}$.

The aim of this study was to compare the changed Ahlbäck radiological classification to the macroscopic examination of the lesions in knee osteoarthritis, and locate the topography of chondral injury of the tibial plateau, linking it to the integrity or lack of integrity of the anterior cruciate ligament. The study was complemented by a biopsy of the most comprised areas caused by the osteoarthritis.

\section{MATERIAL AND METHODS}

We conducted a cross-sectional cohort study including both male and female patients who had a clinical and radiological diagnosis of osteoarthritis and primary indication for total knee arthroplasty.

From July to December 2009, 84 patients fulfilled the proposed criteria. On admission to hospital, radiographs were taken following a standard protocol, and then photographed. All patients underwent total knee arthroplasty performed by the same team of profes- sionals at the Hospital São Bento Cardioclínica, in Belo Horizonte / MG. Pre-surgery photographs were taken of the exposed joint and excised tibial plateau for macroscopic evaluation of the lesions. Osteocartilaginous tissue samples were collected during the surgery, for histological study. After analysis of radiographs and photographs, we selected 40 patients, all with varus deformity, in order to minimize bias due to the quality of the image, which can make the interpretation difficult.

Of the 40 patients, there were 26 females and 14 males, with ages ranging from 48 to 81 years, a mean age of 67.1 years and median of 66.5 years. Of the 40 knees studied, 25 were on the right side and 15 on the left.

The knee radiographs, anteroposterior and lateral views were obtained according to the standard protocol described. Radiograph of the knee in the anteroposterior projection (AP) with one-foot support $^{(5)}$, the beam was centered on the inferior pole of the patella and the film-to-distance was 1 meter. For the lateral view of the knee, the patient was placed in lateral decubitus on the affected side of the knee, with knee flexion of $20^{\circ}$, measured with a goniometer ${ }^{(7)}$. The central ray was directed vertically to the medial knee joint with head angulation of $5^{\circ}$ and a tube-film distance of $1 \mathrm{~m}$. The radiographic image of the medial tibial plateau was distinguished from the lateral view by the method described by Jacobsen $^{(13)}$. All radiographs were performed in the same radiology department (Figure 1).

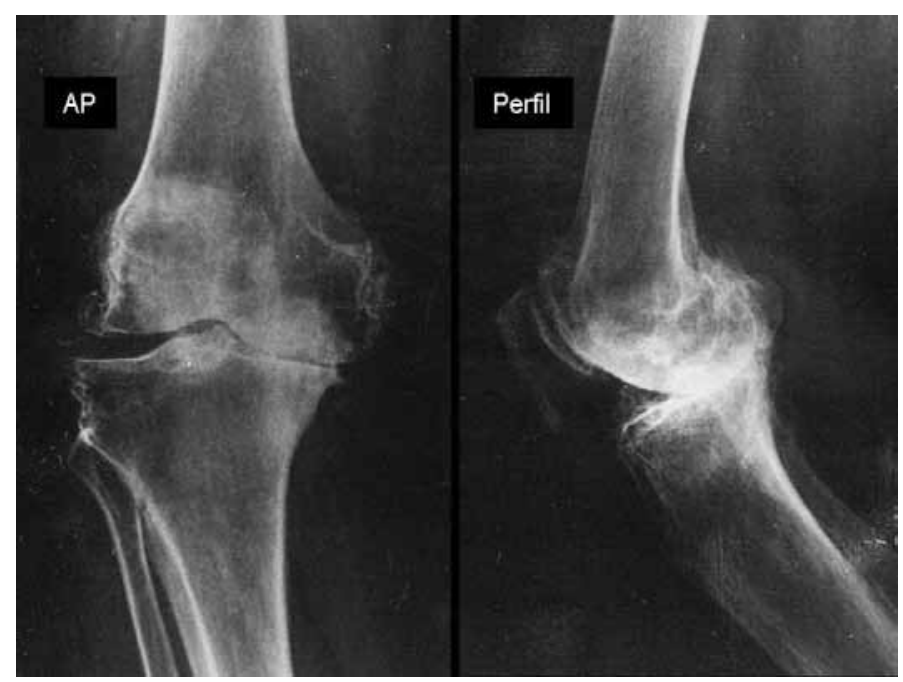

Figure 1 - Right knee radiograph, anteroposterior (AP) and lateral (Perfil) views.

Source: Photos from the Hospital São Bento Cardioclínica archive - BH / MG. 
For the radiological classification of knee osteoarthritis, we used the Ahlbäck classification modified by Keyes et $\mathrm{al}^{(7)}$ (Table 1).

Table 1 - Ahlbäck classification modified by Keyes and Goodfellow.

\begin{tabular}{c|l|l}
\hline Grade & $\begin{array}{c}\text { Radiograph in AP view with } \\
\text { one-foot support }\end{array}$ & $\begin{array}{c}\text { Radiograph in lateral } \\
\text { view with } 20^{\circ} \text { of flexion }\end{array}$ \\
\hline 1 & $\begin{array}{l}\text { Moderate destruction of cartilage } \\
\text { (narrowing of the joint space) }\end{array}$ & $\begin{array}{l}\text { Total destruction of cartilage } \\
\text { (Obliteration or near obliteration of } \\
\text { joint space) }\end{array}$ \\
\hline 3 & $\begin{array}{l}\text { Less than } 5 \mathrm{~mm} \text { wear of the tibial } \\
\text { plateau }\end{array}$ & $\begin{array}{l}\text { Posterior part of the tibial } \\
\text { plateau intact }\end{array}$ \\
\hline 4 & $\begin{array}{l}5 \text { to } 15 \text { mm wear of tibial plateau } \\
\text { posterior tibial plateau } \\
\text { margin }\end{array}$ \\
\hline 5 & $\begin{array}{l}\text { Bone wear greater than } 15 \mathrm{~mm} \\
\text { (severe subluxation of the tibia } \\
\text { relative to femur) }\end{array}$ & $\begin{array}{l}\text { > } 10 \text { mm anterior } \\
\text { subluxation of the tibia }\end{array}$ \\
\hline
\end{tabular}

Source: Translated from: Ahlbäck S, Rydberg J. X-ray classification and examination techniques in gonarthrosis. Läkartidningen. 1980;77(22):2091-3; Keyes GW, Carr AJ, Miller RK, Goodfellow JW. The radiographic classification of medial gonarthrosis. Correlation with operation methods in 200 knees. Acta Orthop Scand. 1992;63(5):497-501.

For macroscopic analysis of injuries of the knee joint (Figure 2) and excised tibial plateau (Figure 3) ICRS (International Cartilage Repair Society) classification of chondral surface and injuries was used, as described ${ }^{(14)}$.

\section{ICRS classification of the chondral surface and injuries:}

\section{Normal:}

Grade 0

\section{Nearly normal:}

Grade 1a - superficial injuries/softening

Grade $1 b-1 a$ and/or surface cracks or fissures

\section{Abnormal:}

Grade $2 \mathrm{a}-$ length $<50 \%$ thickness

\section{Severe injury:}

Grade $3 \mathrm{a}$ - extension $>50 \%$

Grade $3 b$ - to the calcified layer

Grade $3 c$ - to the surface of the subchondral bone (without entering)

Grade $3 \mathrm{~d}$ - includes bulging

\section{Very severe injury:}

Grade $4 \mathrm{a}$ - penetration of the subchondral bone, but not the overall diameter of the defect

Grade $4 b$ - penetration throughout the entire diameter of defect

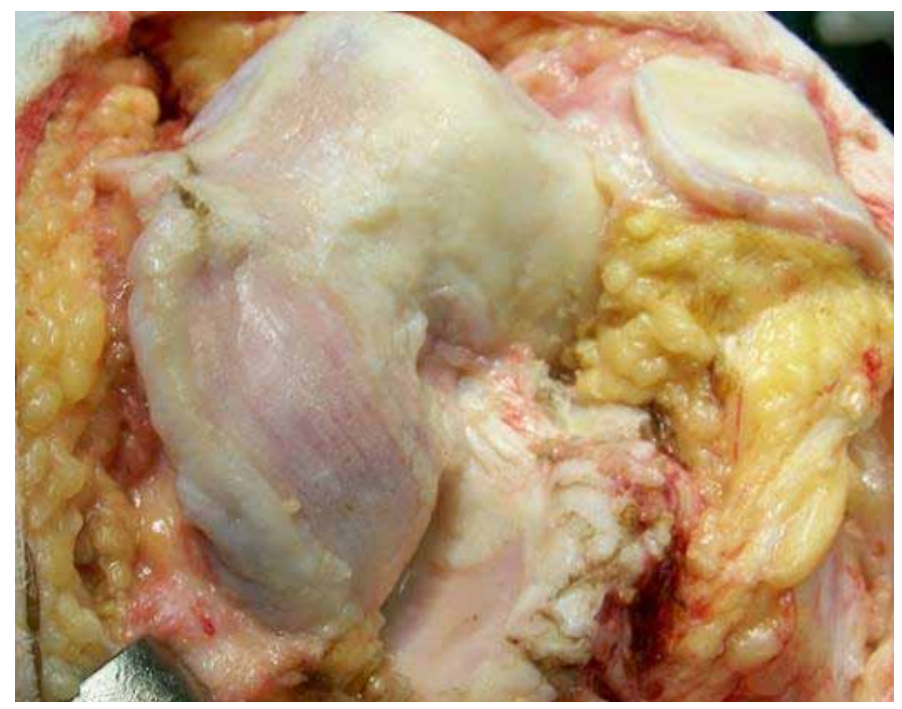

Figure 2 - Preoperative view of the left knee.

Source: Photo from the Hospital São Bento Cardioclínica archive - BH / MG

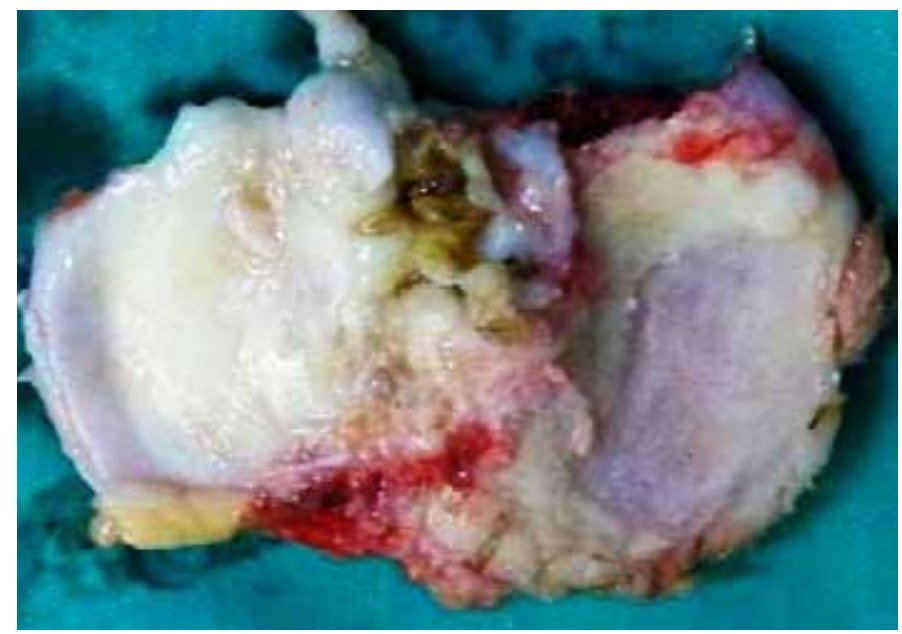

Figure 3 - Preoperative view of excised tibial plateau.

Source: Photo from the Hospital São Bento Cardioclínica archive - BH / MG

To locate the chondral injury and determine whether it is linked to the integrity or lack of integrity of the anterior cruciate ligament (ACL), the medial tibial plateau was divided transversely into four zones: A, $\mathrm{B}, \mathrm{C}$ and D from front to back $^{(8)}$ (Figure 4).

For the histological study, osteocartilaginous tissue samples were collected during total knee arthroplasty surgery, in the areas most affected. The samples were fixed in $10 \%$ formaldehyde and sent to the same laboratory. 


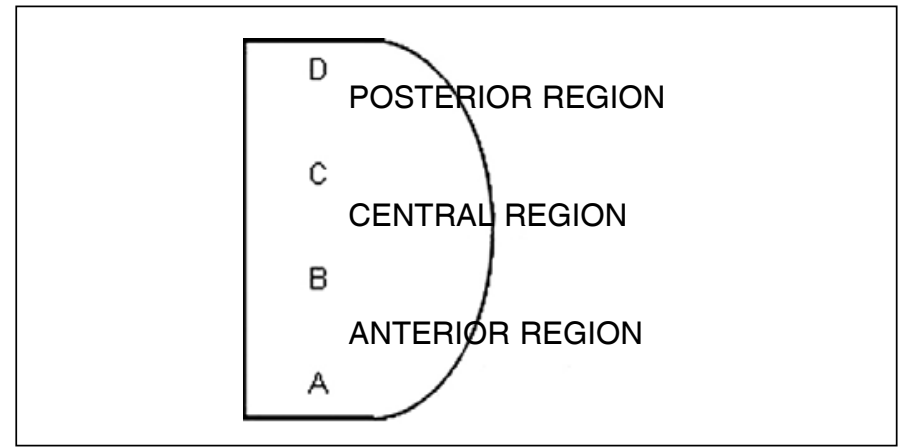

Figure 4 - Drawing of the division of the medial tibial plateau.

\section{RESULTS}

Regarding the Ahlbäck radiological classification modified by Keyes et $\mathrm{al}^{(7)}$, of the 40 knees studied, three $(7.5 \%)$ were classified as grade 1 , two $(5 \%)$ as grade $2,17(42.5 \%)$ as grade $3,16(40 \%)$ as grade 4 and two $(5 \%)$ as grade 5 .

In the macroscopic examination of the knee following the criteria of the ICRS (International Cartilage Repair Society), 25 (62.5\%) patients had very severe injuries and $15(37.5 \%)$ had severe injuries.

Of the 40 patients, $32(80 \%)$ had intact ACL and the injury was located in the anterocentral region of the knee medial tibial plateau. In the eight patients (20\%) with ruptured ACL, the injury extended into the posterior tibial plateau.

The results of microscopic analysis of the material were similar, with the following description: histological sections of the hyaline cartilage showing a reduced number of chondrocytes, also with hypotrophic appearance, with reactive changes, diminished volume nuclei, some even pycnotic. The outer surface of the cartilage also shows small vacuolated areas, sometimes covered with vascular and conjunctiva neoformation. The trabeculae bone show moderate osteoclastic and osteoblastic activity, and conjunctive-vascular neoformation.

In the comparative study between the modified Ahlbäck radiological classification and the macroscopic analysis, ICRS (International Cartilage Repair Society) criteria, demonstrated by plotting the composite column (Figure 5), we observed disagreement between the radiological classification and severity of chondral injury in Ahlbäck's grades 1, 2 and 3. In these grades, chondral injury was severe or very severe. However, when the modified Ahlbäck radiological classification was grade 4 or 5 , there was greater agreement with the ICRS classification for chondral injury.

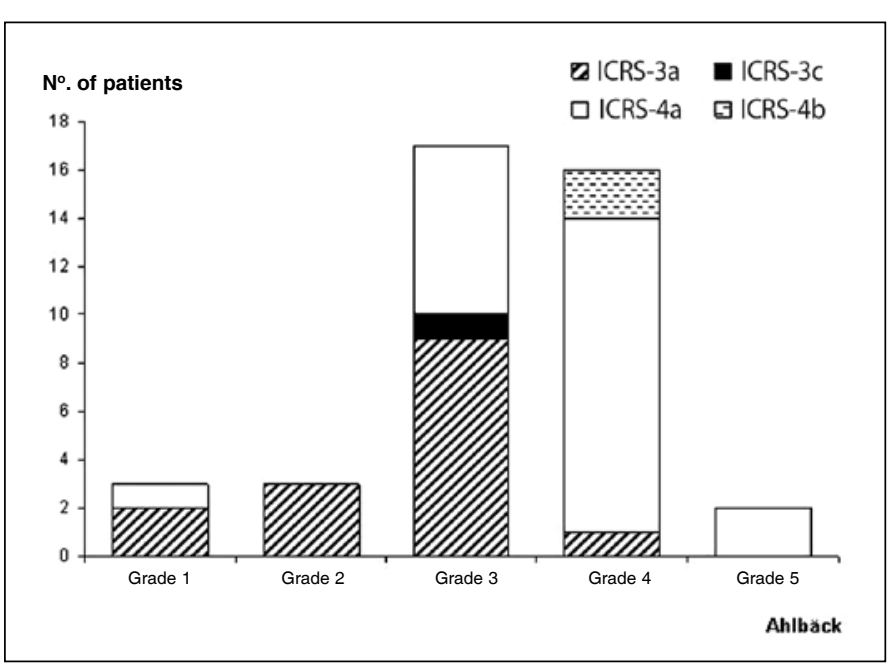

Figure 5 - Comparison between modified Ahlbäck radiological classification and ICRS classification of the chondral surface.

SOURCE: Data obtained from the study, Hospital São Bento Cardioclínica - BH / MG

\section{DISCUSSION}

The treatment of knee osteoarthritis should be based on clinical examination, especially in relation to pain, deformity and disability in patients. The radiographic examination is an imaging method used to classify the grade of the injury, and associated with the clinical examination, it is of use in the surgical conduct.

Ahlbäck $^{(5)}$, based on a radiological study of 370 knees with primary knee osteoarthrosis, demonstrated that the degenerative process was limited to only one compartment of the knee and the medial joint space was 10 times more affected than the lateral. He defined five grades of joint degeneration, from narrowing of the joint space through to subluxation of the joint ${ }^{(6)}$.

The Ahlbäck classification is probably the most commonly used system for classifying knee osteoarthritis, but some difficulties with the classification, such as its reproducibility and reliability, have been recognized by several authors ${ }^{(9,10-12)}$.

In clinical practice, we observe a discrepancy between modified Ahlbäck radiological classification and the intraoperative macroscopic findings, which prompted this research.

This comparative study between the modified Ahlbäck radiological classification and macroscopic analysis, ICRS criteria, showed that for the most severe injuries the macroscopic and radiological findings were similar and were confirmed by the histological 
study. In the Ahlbäck classification grades 1, 2 and 3 - and after a careful clinical examination the patient was indicated for surgery - the macroscopic examination showed severe or very severe chondral injury. This discrepancy can be explained by the difficulty in determining the width of the joint space in the Ahlbäck classification. When the joint space is not totally obliterated, with the femoral and tibial ends close to the joint line, is difficult to determine whether there is bone destruction, sometimes resulting in an incorrect choice between grades 1 and $3^{(10)}$.

It is recognized that the radiographic findings may bear little relation to the symptoms. The width of the joint space, osteophytes, and subchondral changes may occur independently of the clinical syndrome called osteoarthritis. Radiograph is probably the best tool for measuring the progression of osteoarthritis ${ }^{(1)}$.

With regard to the topographic location of the injury in patients with intact ACL, the injury was located in the anterocentral region of the medial tibial plateau. In patients with ruptured ACL, the injury extended into the posterior tibial plateau region, a finding that was also reported by other authors ${ }^{(8)}$. White et $\mathrm{al}^{(8)}$ demonstrated that in osteoarthrosis with intact ACL, tibial erosion by no means reached the posterior tibial plateau. The combination of anterocentral erosion and intact ACL provide a logical explanation for the clinical symptoms. The anterocentral position of the erosion of the joint surface explains why the varus deformity is present in the extension and not in the flexion. The intact cruciate ligaments, working with the preserved joint surface of the lateral compartment,

\section{REFERENCES}

1. Altman R, Asch E, Bole G, Borenstein D, Brandt K, Christy W, et al. Development of criteria for the classification and reporting of osteoarthritis. Classification of osteoarthritis of the knee. Diagnostic and Therapeutic Criteria Committee of the American Rheumatism Association. Arthritis Rheum. 1986;29(8):1039-49.

2. Centers for Disease Control and Prevention (CDC). Arthritis prevalence and activity limitations--United States, 1990. MMWR Morb Mortal Wkly Rep 1994;43(24):433-8.

3. Ravaud P, Chastang C, Auleley GR, Giraudeau B, Royant V, Amor B, et al. Assessment of joint space width in patients with osteoarthritis of the knee: a comparison of 4 measuring instruments. J Rheumatol. 1996;23(10):1749-55.

4. Guermazi A, Hunter DJ, Roemer FW. Plain radiography and magnetic resonance imaging diagnostics in osteoarthritis: Validated staging and scoring J Bone Joint Surg Am. 2009;91(Suppl 1):54-62.

5. Ahlbäck S. Osteoarthrosis of the knee. A radiographic investigation. Acta Radiol Diagn (Stockh). 1968:Suppl 277:7-72.

6. Ahlbäck S, Rydberg J. X-ray classification and examination technics in gonarthrosis. Läkartidningen. 1980;77(22):2091-3

7. Keyes GW, Carr AJ, Miller RK, Goodfellow JW. The radiographic classification of medial gonarthrosis. Correlation with operation methods in 200 knees. Acta Orthop Scand. 1992;63(5):497-501. require the medial femoral condyle to roll back in flexion, out of the previous depression and into the intact cartilage of posterior tibial plateau.

We have observed that in osteoarthritis with intact ACL, the injury begins in the central tibial plateau. When ACL rupture occurs first and the patient develops osteoarthritis, the injury begins in the posterior tibial plateau.

The histological study of osteocartilaginous tissue corroborated the ICRS classification of chondral injuries.

\section{CONCLUSION}

1) Grades 4 and 5 knee osteoarthritis, in the modified Ahlbäck radiological classification, corroborated the macroscopic analysis, ICRS criteria, very severe chondral injury.

2) Grades 1, 2 and 3 knee osteoarthritis, in the modified Ahlbäck radiological classification, have shown disagreement with the macroscopic analysis, ICRS criteria.

3) The location of the injury in the tibial plateau showed correlation with the integrity or non-integrity of ACL. In patients with osteoarthritis and intact $\mathrm{ACL}$, the injury was located in the anterior-central region of the medial tibial plateau, and in patients with ruptured ACL, the lesion extended into the posterior tibial plateau. However, due to the number of cases it was not possible to make a statistical correlation.

4) The osteocartilaginous tissue pathology confirmed the ICRS classification of chondral injuries.

8. White SH, Ludkowski PF, Goodfellow JW. Anteromedimedial osteoarthritis of the knee. J Bone Joint Surg Br. 1991;73(4):582-6.

9. Galli M, Santis V, Tafuro L. Reliability of the Ahlbäck classification of knee osteoarthritis. Osteoarthritis Cartilage. 2003;11(8):580-4.

10. Weidow J, Cederlund CG, Ranstam J, Kärrholm J. Ahlbäck grading of osteoarthritis of the knee. Poor reproducibility and validity based on visual inspection of the joint. Acta Orthop. 2006; 77(2):262-6.

11. Villardi AM, Mandarino M, Veiga LT. Avaliação da reprodutibilidade da classificação de Ahlbäck modificada para osteoartrose do joelho. Rev Bras Ortop. 2006;41(5):157-61.

12. Albuquerque RP, Giordano V, Sturm L, Azevedo Júnior V, Leão A, Amaral NP. Análise da reprodutibilidade de três classificações para a osteoartrose do joelho. Rev Bras Ortop. 2008;43(8):329-35.

13. Jacobsen K. Gonylaxometry: Stress radiographic measurement of passive stability in the knee joints of normal subjects and patients with ligament injuries. Accuracy and range of application. Acta Orthop Scand. 1981;52(Suppl 194):1-263

14. Clinical Münchenwiler Evaluation Group. ICRS Cartilage Injury Evaluation Package. Available at: http://www.cartilage.org/_files/ content management/ ICRS evaluation.pdf. Accessed in December 2009 . 